\title{
Effects of Dehydration Temperatures on Moisture Absorption and Dissolution Behavior of Theophylline
}

\author{
Makoto Ono, ${ }^{*, a, b}$ Yuichi Tozuka, ${ }^{a}$ Toshio Oguchi, ${ }^{a}$ and Keiji Yamamoto ${ }^{a}$ \\ Graduate School of Pharmaceutical Sciences, Chiba University, ${ }^{a}$ 1-33 Yayoi-cho, Inage-ku, Chiba 263-8522, Japan and \\ Chemical Research Center, Daiichi Pharmaceutical Co., Ltd., ${ }^{b}$ 1-16-13 Kita-kasai, Edogawa-ku, Tokyo 134-8630, Japan.
}

Received June 18, 2001; accepted September 7, 2001

\begin{abstract}
Anhydrous theophylline was prepared by heating theophylline monohydrate at temperatures between $60^{\circ} \mathrm{C}$ and $140^{\circ} \mathrm{C}$. The effects of dehydration temperatures on the moisture absorption and dissolution behavior of anhydrous theophylline were investigated in this study. The hydration rate of anhydrous theophylline at $95 \%$ relative humidity and $25^{\circ} \mathrm{C}$ decreased with increasing dehydration temperatures. From the fitting analysis of solidstate reaction models, the hydration reaction was found to be governed by the phase boundary reaction model for samples prepared at lower dehydration temperatures $\left(<100^{\circ} \mathrm{C}\right)$ but the reaction obeyed the growth of nuclei reaction model when samples were dehydrated at higher temperatures. The dissolution rates of various anhydrous theophylline samples were measured by the rotating disk method. The calculated solubility of anhydrous theophylline prepared by heating was about 2.5 times higher than that of theophylline monohydrate. The phase transformation rate from the anhydrous form to the monohydrate during dissolution tests decreased with higher dehydration temperatures. It was found that the anhydrous theophylline prepared at different dehydration temperatures transformed to the monohydrate by way of different growth of hydrate nuclei mechanism.
\end{abstract}

Key words theophylline; dehydration temperature; hydration rate; dissolution rate; solid-state reaction model

Many organic drug substances have corresponding hydrate and solvate forms called pseudo-polymorphic forms. Among them, ampicillin trihydrate and caffeine monohydrate are well-known hydrates. The hydrate-anhydrous form transformation is reversible phase transformation influenced by temperature, relative humidity $(\mathrm{RH})$, particle size, and surface area. This hydrate-anhydrous form transformation was possible to occur during processing or storage of drugs. The evaluation of the hydration and dehydration behavior of drug substances is important in the development of stable formulations because the physicochemical, mechanical and biological properties ${ }^{1,2)}$ of the hydrate forms differ significantly from those of the corresponding anhydrous forms. Thus, it is necessary to clarify the properties of the crystal water molecules in drug substances.

Theophylline is a widely used anti-asthmatic drug. It is well known that theophylline has two anhydrous forms (form I and form II) and a monohydrate. ${ }^{3)}$ The effects of various conditions such as heating, ${ }^{3,4)}$ particle size, ${ }^{5)}$ grinding ${ }^{6)}$ and tableting ${ }^{7)}$ on the dehydration of theophylline monohydrate have already been investigated. The hydration of two anhydrous forms of theophylline was reported by Otsuka et al., ${ }^{8}$ ) as well as the effects of moisture on theophylline tablets. ${ }^{9,10)}$ Moreover, the dissolution rate of theophylline polymorphs was studied. ${ }^{11,12)}$ However, the physicochemical properties of the anhydrous forms obtained under different drying conditions have not yet been investigated.

The drying process of drug substances is performed in the final manufacturing process in many cases; thus, the physicochemical properties of drug substances are influenced significantly by the conditions of this process. In this study, theophylline was chosen as a model drug and the effects of dehydration temperatures of the monohydrate on the moisture absorption behavior and the dissolution rate of its anhydrous form prepared by different heating temperatures were investigated.

\section{Experimental}

Materials Theophylline (Tokyo Kasei, Tokyo, Japan) was of reagent grade. Theophylline monohydrate was recrystallized from distilled water and dried at room temperature. Theophylline monohydrate was classified into three particle sizes using sieves, larger than $250 \mu \mathrm{m}$, between 250 and $75 \mu \mathrm{m}$, and smaller than $75 \mu \mathrm{m}$.

Preparation of Dehydrate Form Theophylline anhydrous form was prepared from its monohydrate by storing at $60,80,100,120$ and $140{ }^{\circ} \mathrm{C}$ for $2 \mathrm{~h}$. The obtained anhydrous forms were stored in desiccator over silica gel.

Differential Scanning Calorimetry (DSC) DSC was performed on the SSC/5200 DSC 220 (Seiko Instruments, Tokyo, Japan). The temperature was calibrated using indium and tin. The operating conditions in the openaluminum pan system were as follows: sample weight, $5 \mathrm{mg}$; heating rate, $10^{\circ} \mathrm{C} / \mathrm{min}$; and nitrogen gas flow rate, $100 \mathrm{ml} / \mathrm{min}$.

Thermogravimetry (TG) TG was performed on the SSC/5200 TG/DTA 220 (Seiko Instruments, Tokyo, Japan). The operating conditions in the open-aluminum pan system were as follows: sample weight, $5 \mathrm{mg}$; heating rate, $10^{\circ} \mathrm{C} / \mathrm{min}$; and nitrogen gas flow rate, $200 \mathrm{ml} / \mathrm{min}$.

Powder X-Ray Diffraction The powder X-ray diffraction patterns of the samples were obtained using an X'Pert-MPD PW 3050 diffractometer (Phillips, Netherlands). Powder samples were presented in the glass holder cavity. The operating conditions were as follows: target, $\mathrm{Cu}$; filter, Ni; voltage, $35 \mathrm{kV}$; current, $20 \mathrm{~mA}$; receiving slit, $0.2 \mathrm{~mm}$; and scanning speed, $0.025^{\circ} 2 \theta / \mathrm{s}$.

Specific Surface Area Specific surface area was measured by low temperature krypton adsorption method. The data were obtained using a micrometritics ASAP 2010 (Shimadzu, Kyoto, Japan). The specific surface areas were calculated by BET method.

Moisture Sorption Behavior The moisture sorption data were obtained using a controlled atmosphere microbalance system, SGA-100 (VTI, U.S.A.). About $20 \mathrm{mg}$ of sample was placed in a glass holder, and the holder was suspended in an isothermal chamber at $25^{\circ} \mathrm{C}$. The RH in chamber was kept at $95 \%$. The weight of the sample was measured every $2 \mathrm{~min}$ by the microbalance, D-200 (Karn, U.S.A.). The experiment continued until the equilibrium weight of the sample was reached. The water content of the equilibrated sample was analyzed by TG.

Dissolution Study by Dispersed Amount Method The dissolution profiles of the monohydrate and the anhydrous forms prepared by heating the monohydrate at various temperatures were measured in water at $15{ }^{\circ} \mathrm{C}$. About $700 \mathrm{mg}$ of sample was added to $50 \mathrm{ml}$ of water and vigorously stirred by a magnetic stirrer. Aliquots of the solution were withdrawn with a syringe at definite time intervals. The solution was passed through a membrane filter $(0.45 \mu \mathrm{m})$ and then diluted with water appropriately. The concentration of theophylline in solution was measured by using an ultraviolet spectrophotometer UV230 (Hitachi, Tokyo, Japan) at an absorbance wavelength of 
$272 \mathrm{~nm}$.

Intrinsic Dissolution Rate Study The intrinsic dissolution rates of the monohydrate and the anhydrous forms prepared by heating the monohydrate at various temperatures were measured by the rotating disk method. Four hundred milligrams of sample was pressed into a disk, $13 \mathrm{~mm}$ in diameter, at $200 \mathrm{~kg} / \mathrm{cm}^{2}$ for $5 \mathrm{~min}$. It was confirmed by powder X-ray diffraction analysis that the solid-solid transformation did not occur during the disk preparation.

The disk was rotated at $100 \mathrm{rpm}$ in $50 \mathrm{ml}$ water at $15^{\circ} \mathrm{C}$. The sample solution was circulated into a flow cell by a peristaltic pump and the concentration of sample in solution was measured by an ultraviolet spectrophotometer UV230 (Hitachi, Tokyo, Japan) at an absorbance wavelength of $280 \mathrm{~nm}$.

\section{Results and Discussion}

Identification of Prepared Samples DSC and TG curves for two forms of theophylline are shown in Fig. 1. The monohydrate showed a broad endothermic peak around 60 $90^{\circ} \mathrm{C}$ and a sharp endothermic peak at $272^{\circ} \mathrm{C}$. The first endothermic peak was due to dehydration and weight loss of $8.9 \%$ from approximately 40 to $90^{\circ} \mathrm{C}$ shown on the $\mathrm{TG}$ curve. The stoichiometric value calculated for the monohydrate dehydration was $9.1 \%$ and this value was almost identical with the value obtained from the TG analysis. The second endothermic peak was due to melting of the anhydrous form. On the other hand, the anhydrous form prepared by heating at $60^{\circ} \mathrm{C}$ showed only one endothermic peak at $272^{\circ} \mathrm{C}$ due to melting of the anhydrous theophylline and no weight loss was shown on the TG analysis. The DSC pattern of the anhydrous form was identified to the pattern of form II theophylline described by Suzuki et al. ${ }^{3)}$ All anhydrous forms prepared by heating at different temperatures exhibited the similar DSC and TG patterns as that prepared at $60^{\circ} \mathrm{C}$. The enthalpy of fusion at $272{ }^{\circ} \mathrm{C}$ of the anhydrous form prepared at 60,100 and $140{ }^{\circ} \mathrm{C}$ were $29.3 \pm 0.22,29.6 \pm 0.22$ and $29.8 \pm 0.26 \mathrm{~kJ} / \mathrm{mol}$, respectively. The observed enthalpy of fusion slightly varied with the anhydrous forms which were prepared at different heating temperatures.

The powder X-ray diffraction patterns of the monohydrate and anhydrous forms prepared at 60,100 and $140{ }^{\circ} \mathrm{C}$ are shown in Fig. 2. The patterns of all anhydrous forms were the almost same but were quite different from the monohydrate. The patterns of the anhydrous forms were consistent with the pattern reported by Suzuki et al. ${ }^{3)}$

Consequently, all anhydrous forms prepared by heating at different temperatures had the same crystal form and were identified as form II.

Moisture Sorption Behavior The isothermal hydration profiles at $95 \% \mathrm{RH}$ and $25^{\circ} \mathrm{C}$ of unfractionated anhydrous forms prepared by heating at various temperatures are shown in Fig. 3. The weight of all anhydrous forms increased with duration of storage time and all the anhydrous forms finally transformed to the monohydrate. The transformation of the stored samples to monohydrate was confirmed by the DSC and TG patterns. The anhydrous form prepared by heating at $60{ }^{\circ} \mathrm{C}$ transformed to the monohydrate after $4 \mathrm{~h}$ exposure to $95 \% \mathrm{RH}$ atmosphere, while the anhydrous form prepared by heating at $140^{\circ} \mathrm{C}$ showed a slower transformation rate of more than $15 \mathrm{~h}$ after exposure to $95 \% \mathrm{RH}$ atmosphere. It was found that the moisture absorption rate of anhydrous forms decreased with increasing heating temperature.

It is well known that the moisture absorption rate depended on the specific surface area and increased with increasing specific surface area. The specific surface areas of anhydrous forms prepared by heating at various temperatures

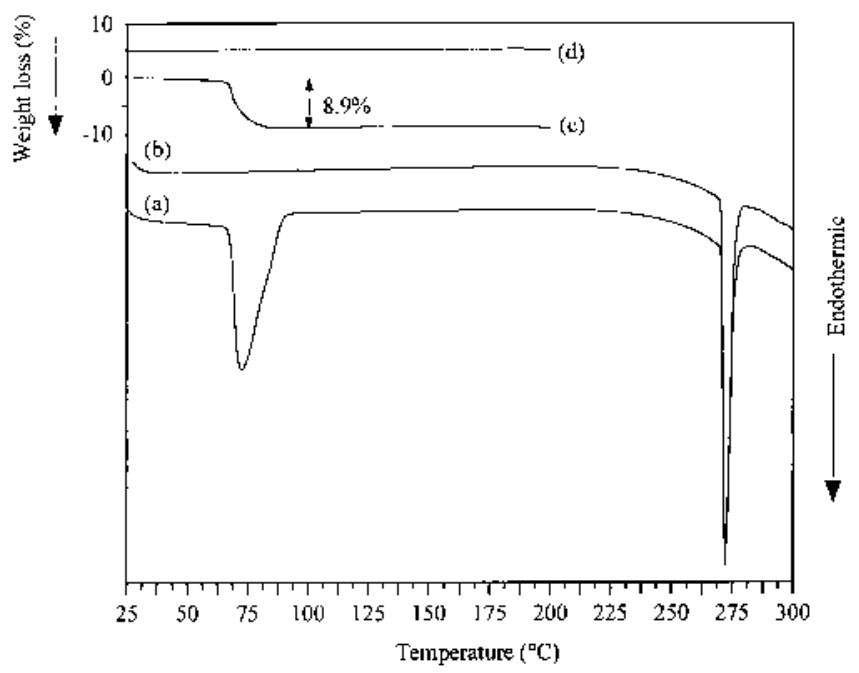

Fig. 1. DSC and TG Curves of Theophylline Monohydrate and Anhydrous Form

(a) DSC curve of monohydrate, (b) DSC curve of anhydrous form prepared at $60^{\circ} \mathrm{C}$, (c) TG curve of monohydrate, (d) TG curve of anhydrous form prepared at $60^{\circ} \mathrm{C}$

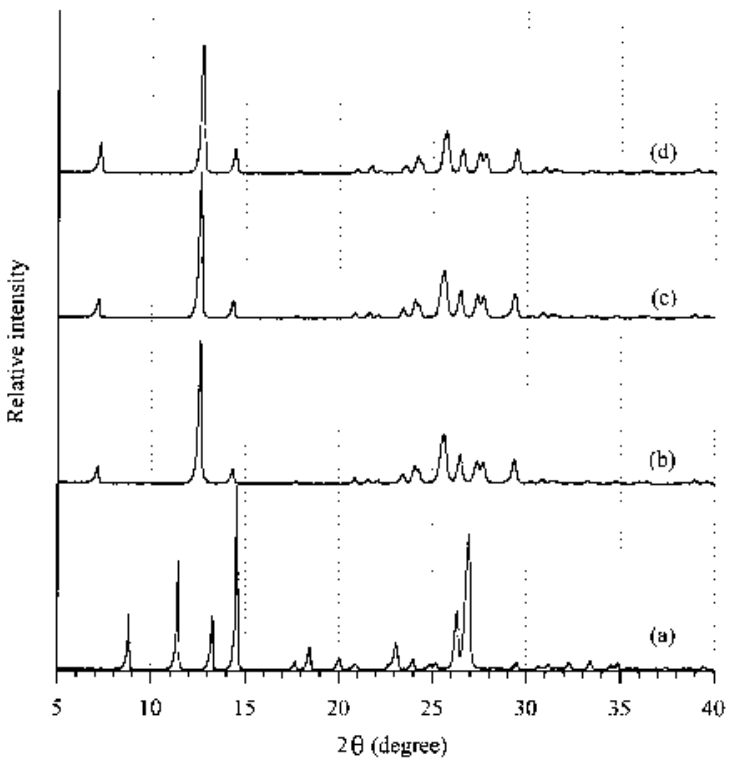

Fig. 2. Powder X-Ray Diffraction Patterns of Theophylline Monohydrate and Various Anhydrous Theophylline

(a) Monohydrate, (b) anhydrous form prepared at $60^{\circ} \mathrm{C}$, (c) anhydrous form prepared at $100{ }^{\circ} \mathrm{C},(\mathrm{d})$ anhydrous form prepared at $140{ }^{\circ} \mathrm{C}$.

are shown in Table 1. Since the specific surface areas were almost the same in all anhydrous forms prepared at different heating temperatures, it was clear that the difference in the hydration rate among various anhydrous forms were not due to differences in specific surface area. The isothermal hydration profiles at $95 \% \mathrm{RH}$ and $25^{\circ} \mathrm{C}$ for the fractionated anhydrous forms prepared by heating at $80{ }^{\circ} \mathrm{C}$ are shown in Fig. 4 . The hydration rate depended on particle sizes and increased with a decrease in particle sizes. As the surface area increases with a decrease in particle sizes, this phenomenon can be explained on the basis of different surface area.

The analysis of moisture absorption rate was performed using the solid-state reaction models shown in Table $2 .{ }^{13)}$ For the analysis, the hydration data between $5 \%$ and $95 \%$ were 
used in the analysis. The best fit solid-state reaction mechanism for the hydration of theophylline anhydrous forms are shown in Table 3. All particle sizes of the anhydrous forms prepared by heating at $60^{\circ} \mathrm{C}$ fitted with the three-dimensional phase boundary reaction model. The hydration mechanism for the anhydrous forms prepared at $100^{\circ} \mathrm{C}$ obeyed the two-dimensional growth nuclei model and the anhydrous forms prepared at $140^{\circ} \mathrm{C}$ obeyed the three-dimensional growth nuclei model. These results suggested that the hydration mechanism of anhydrous theophylline changed from phase boundary reaction to growth nuclei model at the heating temperature of $100^{\circ} \mathrm{C}$. It was assumed that the hydration reaction of the anhydrous form prepared by heating at low temperatures $\left(<100^{\circ} \mathrm{C}\right)$ progressed gradually from the surface of the particle to the inside of the particle. On the other hand, the hydration reaction of the anhydrous form prepared at higher temperatures $\left(>100^{\circ} \mathrm{C}\right)$ occurred by the growth of nuclei at random position in the particles. Consequently, the hydration mechanism of anhydrous theophylline prepared by heating the monohydrate depended on the heating temperature.

The half-lives of hydration reactions of anhydrous forms prepared by heating at various temperatures were calculated from the rate constant obtained from the best fit solid-state

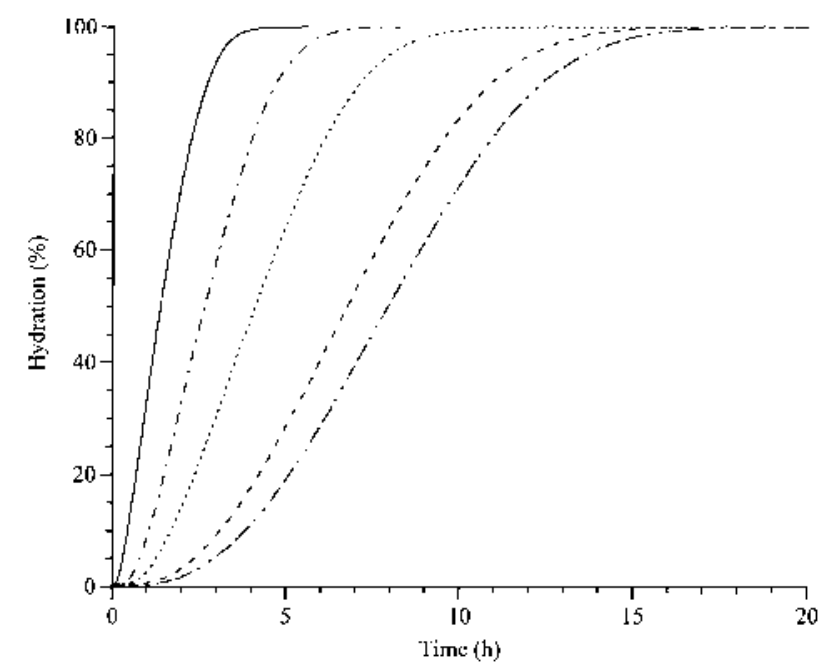

Fig. 3. Isothermal Hydration Profiles at $95 \% \mathrm{RH}$ and $25^{\circ} \mathrm{C}$ for Unfractionated Anhydrous Theophylline Prepared by Heating at Various Temperatures

Heating temperature:,$- 60{ }^{\circ} \mathrm{C} ; \cdot \cdots \cdot \cdot-\cdot, 80^{\circ} \mathrm{C} ; \cdots \cdots \cdot, 100^{\circ} \mathrm{C} ;-\cdots, 120^{\circ} \mathrm{C} ; \cdots \cdots \cdot-$ $140{ }^{\circ} \mathrm{C}$. reaction model. The relationships between the heating temperatures during preparation of the anhydrous forms and the half-lives of hydration reaction of theophylline are shown in Fig. 5. The half-life increased with an increase in the heating temperature regardless of the particle size. The anhydrous forms prepared at lower temperatures showed shorter halflives, whereas those prepared at higher temperatures showed longer half-lives. The hydration reaction of the anhydrous form prepared at $140{ }^{\circ} \mathrm{C}$ required 13 times longer to complete compared to that of the anhydrous form prepared at $60{ }^{\circ} \mathrm{C}$. Thus, a stable anhydrous form that is resistant to humidity could be obtained by controlling the heating temperature.

Table 1. Specific Surface Area of Anhydrous Theophylline Prepared by Heating at Various Temperatures

\begin{tabular}{cc}
\hline \hline Heating temperature $\left({ }^{\circ} \mathrm{C}\right)$ & Specific surface area $\left(\mathrm{m}^{2} / \mathrm{g}\right)$ \\
\hline 60 & 0.346 \\
80 & 0.374 \\
100 & 0.325 \\
120 & 0.311 \\
140 & 0.333 \\
\hline
\end{tabular}

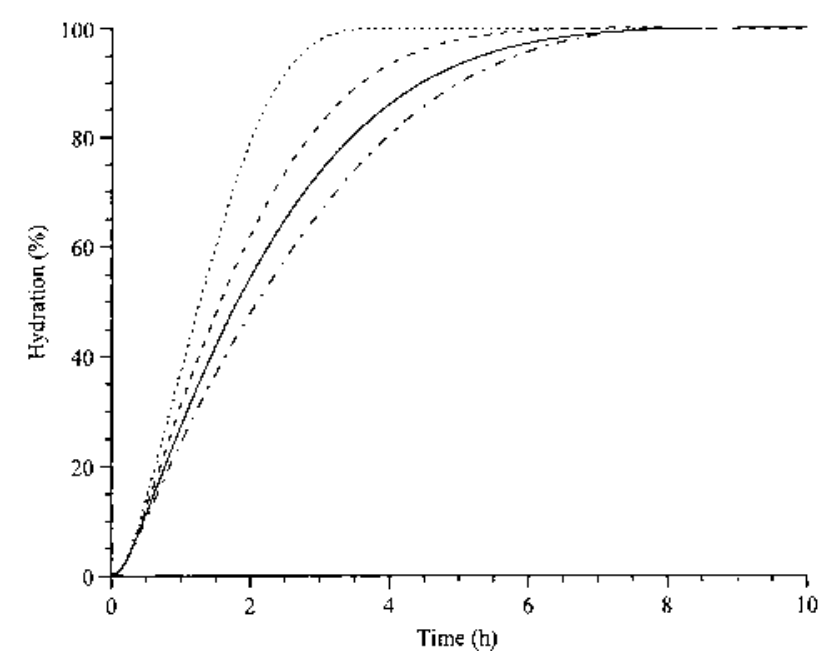

Fig. 4. Isothermal Hydration Profiles at $95 \% \mathrm{RH}$ and $25^{\circ} \mathrm{C}$ for Anhydrous Forms of Theophylline Prepared by Heating at $80^{\circ} \mathrm{C}$

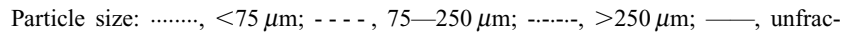
tionated.

Table 2. Solid-State Reaction Rate Equations and Mechanisms

\begin{tabular}{lll}
\hline \hline Function & \multicolumn{1}{c}{ Equation $^{a)}$} & \\
& $\alpha=k t$ & Mechanism \\
$\mathrm{R} 1(\alpha)$ & $1-(1-\alpha)^{1 / 2}=k t$ & Zero-order mechanism (Polany-Wigner equation) \\
$\mathrm{R} 2(\alpha)$ & $1-(1-\alpha)^{1 / 3}=k t$ & Phase boundary reaction, cylindrical symmetry \\
$\mathrm{R} 3(\alpha)$ & $-\ln (1-\alpha)=k t$ & Random nucleation, one nucleus on each particle \\
$\mathrm{F} 1(\alpha)$ & $(-\ln (1-\alpha))^{1 / 2}=k t$ & Random nucleation, two-dimensional growth of nuclei (Avrami-Erofe'ev equation) \\
$\mathrm{A} 2(\alpha)$ & $(-\ln (1-\alpha))^{1 / 3}=k t$ & Random nucleation, three-dimensional growth of nuclei (Avrami-Erofe'ev equation) \\
$\mathrm{A} 3(\alpha)$ & $(1-\alpha) \ln (1-\alpha)+\alpha=k t$ & One-dimensional diffusion \\
$\mathrm{D} 1(\alpha)$ & $\left(1-(1-\alpha)^{1 / 3}\right)^{2}=k t$ & Two-dimensional diffusion \\
$\mathrm{D} 2(\alpha)$ & $(1-2 \alpha / 3)-(1-\alpha)^{2 / 3}=k t$ & Three-dimensional diffusion (Jander equation) \\
$\mathrm{D} 3(\alpha)$ & Three-dimensional diffusion (Ginstling-Brounshtein equation) \\
$\mathrm{D} 4(\alpha)$ &
\end{tabular}


Table 3. Solid-State Reaction Model for the Hydration Reaction of Anhydrous Theophylline Prepared by Heating at Various Temperatures

\begin{tabular}{lccccc}
\hline \hline \multirow{2}{*}{ Particle size } & \multicolumn{5}{c}{ Heating temperature $\left({ }^{\circ} \mathrm{C}\right)$} \\
\cline { 2 - 6 } & 60 & 80 & 100 & 120 & 140 \\
\hline$r<75 \mu \mathrm{m}$ & $\mathrm{R} 3$ & $\mathrm{~A} 2$ & $\mathrm{~A} 2$ & $\mathrm{~A} 3$ & $\mathrm{~A} 3$ \\
$75 \mu \mathrm{m}<r<250 \mu \mathrm{m}$ & $\mathrm{R} 3$ & $\mathrm{R} 3$ & $\mathrm{~A} 2$ & $\mathrm{~A} 2$ & $\mathrm{~A} 3$ \\
$r>250 \mu \mathrm{m}$ & $\mathrm{R} 3$ & $\mathrm{R} 3$ & $\mathrm{~A} 2$ & $\mathrm{~A} 2$ & $\mathrm{~A} 3$ \\
Unfractioned & $\mathrm{R} 3$ & $\mathrm{R} 3$ & $\mathrm{~A} 2$ & $\mathrm{~A} 2$ & $\mathrm{~A} 3$ \\
\hline
\end{tabular}

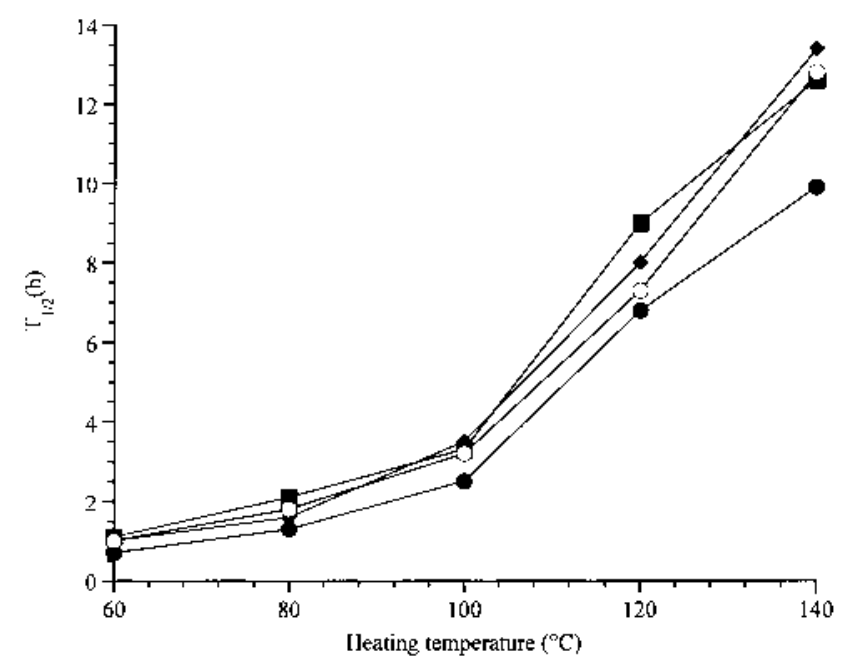

Fig. 5. Relationship between Heating Temperature for Preparing Anhydrous Form and Half-Life of Hydration Reaction of Theophylline

Particle size: $\bullet,<75 \mu \mathrm{m} ; \bullet, 75-250 \mu \mathrm{m} ; \mathbf{\square},>250 \mu \mathrm{m}$; O, unfractionated.

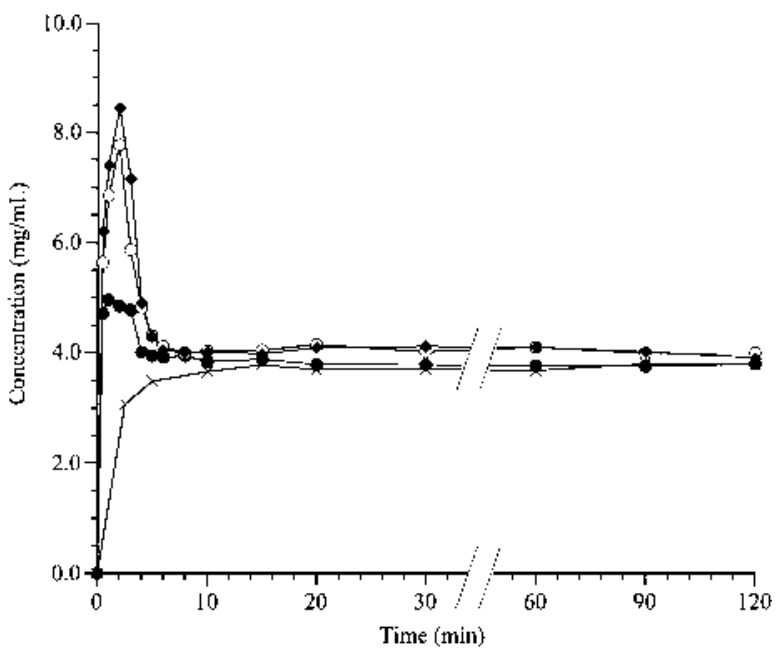

Fig. 6. Dissolution Profiles in Water at $15{ }^{\circ} \mathrm{C}$ for Theophylline Monohydrate and Anhydrous Forms of Theophylline Prepared by Heating at Various Temperatures

○, anhydrous form prepared at $60^{\circ} \mathrm{C} ; \bigcirc$, anhydrous form prepared at $100^{\circ} \mathrm{C}$; hydrous form prepared at $140^{\circ} \mathrm{C} ; \times$, monohydrate.

Dissolution Behavior by Dispersed Amount Method The dissolution behaviors of the monohydrate and anhydrous forms prepared by heating at various temperatures were investigated by the dispersed amount method in water at $15^{\circ} \mathrm{C}$. The dissolution profiles are shown in Fig. 6. The maximum concentrations of the anhydrous forms were observed in the

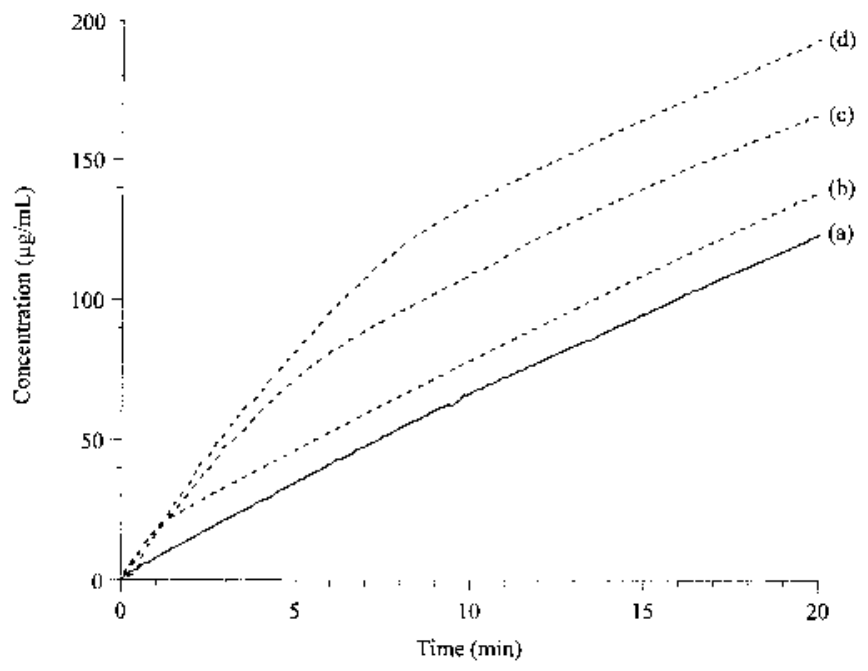

Fig. 7. Initial Dissolution Curves at $15^{\circ} \mathrm{C}$ in Water for Theophylline Monohydrate and Anhydrous Forms of Theophylline Prepared by Heating at Various Temperatures

(a) Monohydrate, (b) anhydrous form prepared at $60^{\circ} \mathrm{C}$, (c) anhydrous form prepared at $100{ }^{\circ} \mathrm{C},(\mathrm{d})$ anhydrous form prepared at $140^{\circ} \mathrm{C}$.

initial dissolution stage, and then the concentrations decreased gradually. Finally, the concentrations of the anhydrous forms reached the equilibrium concentration which was the same as the monohydrate. The anhydrous forms showed characteristic convex dissolution curves and this suggested that the phase transformation occurred during the dissolution process in water. The apparent saturated concentration of the anhydrous form prepared by heating at $140{ }^{\circ} \mathrm{C}$ was about $8.5 \mathrm{mg} / \mathrm{ml}$, while that of anhydrous form prepared at $60^{\circ} \mathrm{C}$ was about $5.0 \mathrm{mg} / \mathrm{ml}$. The apparent supersaturated concentration of individual anhydrous form prepared by heating at different temperatures increased with increasing heating temperature. Since the anhydrous form prepared by heating at $60{ }^{\circ} \mathrm{C}$ transformed rapidly to the monohydrate in water, it was assumed that the apparent supersaturated concentration of the anhydrous form prepared at $60^{\circ} \mathrm{C}$ could not reach the solubility of the anhydrous form. These results were in good agreement with the results indicating the hydration rate at $95 \% \mathrm{RH}$ increased with decrease in heating temperature. Therefore, these results suggested that the hydration reaction of anhydrous theophylline was inhibited by higher dehydration temperature.

Intrinsic Dissolution Rate The intrinsic dissolution rate was determined by the rotation disk method at $15^{\circ} \mathrm{C}$. The dissolution curves of the anhydrous forms prepared by heating at 60,100 and $140{ }^{\circ} \mathrm{C}$ are shown in Fig. 7 along with that of the monohydrate. The initial dissolution rates of the all anhydrous forms were identical but the required time in arriving at the bending region on the dissolution curves were different from each other. After the bending region, the slopes of dissolution curves of the anhydrous forms were similar to that of the monohydrate.

According to the study by Nogami et al., ${ }^{14)}$ the dissolution parameters could be calculated from the dissolution curves using the following equations:

$$
\begin{aligned}
& d C / d t=k_{\mathrm{t}} C_{\mathrm{SH}} \\
& (d C / d t)_{t=0}=k_{\mathrm{t}} C_{\mathrm{SA}}
\end{aligned}
$$


Table 4. Dissolution Parameters Obtained from the Rotating Disk Experiments of Anhydrous Theophylline and Monohydrate in Water at $15^{\circ} \mathrm{C}$

\begin{tabular}{lcccc}
\hline \hline & $\begin{array}{c}\text { Initial slope } \\
{[\mu \mathrm{g} /(\mathrm{ml} \cdot \mathrm{min})]}\end{array}$ & $\begin{array}{c}k_{\mathrm{t}} \\
\left(\mathrm{min}^{-1}\right)\end{array}$ & $\begin{array}{c}\text { Solubility } \\
(\mathrm{mg} / \mathrm{ml})\end{array}$ & $\begin{array}{c}k_{\mathrm{r}} \\
\left(\mathrm{min}^{-1}\right)\end{array}$ \\
\hline Monohydrate & - & 0.0016 & 3.75 & - \\
Dehydrated at $60^{\circ} \mathrm{C}$ & 15.1 & - & 9.25 & 0.59 \\
Dehydrated at $100^{\circ} \mathrm{C}$ & 15.7 & - & 9.63 & 0.23 \\
Dehydrated at $140^{\circ} \mathrm{C}$ & 15.6 & - & 9.57 & 0.15 \\
\hline
\end{tabular}

$$
b=k_{\mathrm{t}}\left(C_{\mathrm{SA}}-C_{\mathrm{SH}}\right) / k_{\mathrm{r}}
$$

where $C$ represents the concentration of theophylline in bulk solution, $t$ is the time, $k_{\mathrm{t}}$ and $k_{\mathrm{r}}$ represent the rate constant of transport process and phase transformation process, respectively. $C_{\mathrm{SH}}$ and $C_{\mathrm{SA}}$ represent the saturated concentration of monohydrate and anhydrous form, respectively. The $C_{\mathrm{SH}}$ can be obtained from the dispersed amount method described above. The parameters, $k_{\mathrm{t}}, k_{\mathrm{r}}$, and $C_{\mathrm{SA}}$, were calculated from above equations and the results are shown in Table 4. The saturated concentrations of anhydrous forms prepared by heating at different temperatures were calculated to be about $9.5 \mathrm{mg} / \mathrm{ml}$. This value was similar to the maximum concentration of anhydrous form prepared at $140{ }^{\circ} \mathrm{C}$ observed in the dispersed amount method.

On the other hand, the rate constant of phase transformation process from the anhydrous form to the monohydrate decreased with increasing heating temperature. The rate of transformation of the anhydrous form prepared at $60^{\circ} \mathrm{C}$ was about 4 times greater than that of the anhydrous form prepared at $140{ }^{\circ} \mathrm{C}$. Since the phase transformation process from the anhydrous form to the monohydrate was closely related to the hydration mechanism of the anhydrous form, it was thought that there were two possible reasons for the different hydration mechanisms of anhydrous forms prepared at different heating temperature. One reason might be due to crystal lattice defects. Lattice defects might occur in the anhydrous crystals during the dehydration process of the monohydrate by heating. The number of lattice defects might be dependent on the heating temperature during the preparation of the anhydrous forms, that is, the lattice defects were greater in anhydrous form prepared at low heating temperatures. Thus, the anhydrous forms prepared at lower temperatures were imperfect anhydrous crystals owing to the low energy provided by the lower heating temperature. For samples prepared at low temperatures, fast hydration reaction might be a result of fast water vapor absorption due to the lattice defects. Consequently, because the hydration reaction occurred rapidly upon contact with moisture, the hydration reaction obeyed to phase boundary model. On the other hand, the anhydrous form prepared at higher temperatures which had little lattice defects was gradually hydrated through the growth of nuclei from the anhydrous crystals upon contact with moisture. Another reason was the possibility of change in crystal surface property. The anhydrous crystal shape was similar to that of the monohydrate crystals which were long columnar crystals. But in crystallography, the different powder properties could be caused by the development of hydrophobic plane or change of molecular arrangement at the crystal surface by heating. Such phenomenon was observed in heat-treated hydroxyapatite. ${ }^{15)}$ The change of the surface property such as smoothing of the surface, topological change and variation of pore structure by heating at higher temperatures was able to explain the different hydration mechanisms.

The results of hydration at $95 \% \mathrm{RH}$ and the dissolution behavior of the anhydrous forms prepared by heating at different temperatures suggested that the hydration rate of the anhydrous forms was determined by the hydration mechanism of the anhydrous form. Thus, it was thought that the hydration mechanism was determined by the numbers of lattice defects and the crystal surface property.

\section{Conclusions}

The moisture absorption and the dissolution behavior of anhydrous theophylline prepared at different heating temperatures were investigated. The rate of hydration at $95 \% \mathrm{RH}$ and $25^{\circ} \mathrm{C}$ as well as in water decreased with increasing heating temperature. The results also indicated that anhydrous theophylline prepared at different dehydration temperatures transformed from the anhydrous form to the monohydrate by way of different mechanisms, phase boundary reaction model at lower dehydration temperatures and growth nuclei model at higher dehydration temperatures.

\section{References}

1) Kahela P., Aaltonen R., Lewing E., Anttila M., Kristoffersson E., Int. J. Pharm., 14, 103-112 (1983).

2) Kobayashi Y., Ito S., Itai S., Yamamoto K., Int. J. Pharm., 193, 137146 (2000).

3) Suzuki E., Shimomura K., Sekiguchi K., Chem. Pharm. Bull., 37, 493-497 (1989).

4) Duddu S. P., Das N. G., Kelly T. P., Sokoloski T. D., Int. J. Pharmaceut., 114, 247-256 (1995).

5) Agbada C. O., York P., Int. J. Pharm., 106, 33- 40 (1994)

6) Puttipipatkhachorn S., Yonemochi E., Oguchi T., Yamamoto K., Nakai Y., Chem. Pharm. Bull., 38, 2233-2236 (1990).

7) Otsuka M., Kaneniwa N., Chem. Pharm. Bull., 36, 4914-4920 (1988).

8) Otsuka M., Kaneniwa N., Kawakami K., Umezawa O., J. Pharm. Pharmacol., 42, 606-610 (1990).

9) Otsuka M., Kaneniwa N., Otsuka K., Kawakami K., Umezawa O., Matsuda Y., J. Pharm. Sci., 81, 1189-1193 (1992).

10) Ando H., Ishii M., Kayano M., Ozawa H., Drug Devl. Ind. Pharm., 18, 453-467(1992).

11) Serajuddin A. T. M., Jarowski C. I., J. Pharm. Sci., 74, 148-154 (1985).

12) De Smidt J. H., Fokkens J. G., Grijseels H., Crommelin D. J. A., J. Pharm. Sci., 75, 497-501 (1986).

13) Sharp J. H., Brindley G. W., Achar B. N. N., J. Am. Ceram. Soc., 49, 379-388 (1966).

14) Nogami H., Nagai T., Yotsuyanagi T., Chem. Pharm. Bull., 17, 499509 (1969).

15) Yamamoto K., Muhammad N. A., Higuchi W. I., Fox J. L., J. Colloid Interface Sci., 110, 459-467 (1986). 